\title{
Reinforcing styrene butadiene rubber with lignin-novolac epoxy resin networks
}

\author{
P. Yu, H. He*, C. Jiang, D. Wang, Y. Jia, L. Zhou, D. M. Jia \\ School of Materials Science and Engineering, South China University of Technology, 510641 Guangzhou, People's \\ Republic of China
}

Received 18 June 2014; accepted in revised form 6 August 2014

\begin{abstract}
In this study, lignin-novolac epoxy resin networks were fabricated in the styrene butadiene rubber (SBR) matrix by combination of latex compounding and melt mixing. Firstly, SBR/lignin compounds were co-coagulated by SBR latex and lignin aqueous solution. Then the novolac epoxy resin (F51) was added in the SBR/lignin compounds by melt compounding method. F51 was directly cured by lignin via the ring-opening reaction of epoxy groups of F51 and OH groups (or $\mathrm{COOH}$ groups) of lignin during the curing process of rubber compounds, as was particularly evident from Fourier transform infrared spectroscopy (FTIR) studies and maximum torque of the curing analysis. The existence of lignin-F51 networks were also detected by scanning electron microscope (SEM) and dynamic mechanical analysis (DMA). The structure of the SBR/lignin/F51 was also characterized by rubber process analyzer (RPA), thermogravimetric analysis (TGA) and determination of crosslinking density. Due to rigid lignin-F51 networks achieved in SBR/lignin/F51 composites, it was found that the hardness, modulus, tear strength, crosslinking density, the temperature of 5 and $10 \%$ weight-loss were significantly enhanced with the loading of F51.
\end{abstract}

Keywords: rubber, reinforcements, lignin, novolac epoxy resin, interpenetrating polymer networks

\section{Introduction}

The copolymer Styrene butadiene rubber (SBR), a general-purpose synthetic elastomer widely used in the rubber industry, is nonpolar and noncrystalline with a low gum tensile strength. Therefore, a reinforcing filler is often required in this matrix to improve the physic mechanical properties of SBR composites and reduce the material cost [1,2]. Lignin, one of the most abundant biopolymers on earth, is a polyphenolic macromolecule which is comprised of 9-carbon phenol propane units (p-coumaryl alcohol, coniferyl alcohol, and sinapyl alcohol) linked together by different types of bonds. Large amounts of lignin have been generated by the papermaking industry and emerging cellulosic ethanol production [3]. Lignin is mainly used as a low-grade fuel and its potential is not fully exploited. It is economically and environmentally desirable to convert lignin into valuable reinforcing additives for rubbers. Various academic papers regarding preparations of rubber/ lignin compounds have been published [4-8]. Most recently, Xiao et al. [1] prepared styrene-butadiene rubber/lignin-layered double hydroxide composites by melt mixing. Jiang et al. [9] fabricated natural rubber/nano-lignin composites. Jiang et al. [10] also fabricated cationic lignin/montmorillonite nanosheets and used it to reinforce SBR. Frigerio et al. [11] prepared lignin modified by hexamethylenetetramine as a filler for styrene butadiene rubber. Liao et al. [12] and Cao et al. [13] fabricated a lignin-montmorillonite complex as a novel rubber filler and used it in acrylonitrile butadiene rubber composites. Bahl and Jana [14] modified lignosulfonate by cyclohexylamine and used it as a filler into SBR. Bahl et al.

\footnotetext{
${ }^{*}$ Corresponding author, e-mail: pshuihe@scut.edu.cn

(C) BME-PT
} 
[15] also exploited non-covalent interactions between lignin and carbon black to lower the viscoelastic dissipation in rubber compounds.

Numerous scientific articles relating to preparations of lignin as curing agent in epoxy resin have been published [16, 17]. Self-crosslinkable lignin/epoxidized natural rubber composites were prepared by the ring-opening reaction between lignin and epoxidized natural rubber in our research group [18]. Epoxy resins also have been synthesized by an insitu vulcanization to reinforce SBR [19]. Meanwhile, various interpenetrating polymer networks in the rubber compounds have been prepared [20-23]. However, to the best of our knowledge, there is no report about lignin-novolac epoxy resin networks reinforced SBR. Novolac epoxy resin (F51) was incorporated into SBR/lignin compounds to form lignin-F51 networks composites by in-situ reaction between epoxy groups of F51 and $\mathrm{OH}$ groups (or $\mathrm{COOH}$ groups) of lignin at the vulcanization condition of the rubber, therefore it could be pointed out that the lignin acts not only as a reinforcing agent but also as a crosslinking agent of F51. Thanks to the whole strong lignin-F51 networks constructed in the rubber matrix, the stress is partially transferred by lignin-F51 networks themselves, thus the reinforcement will not be so much dependent on the interfacial properties, polarity discrepancy and dispersion of the filler, which were traditionally considered as crucial factors of reinforcement for the polymer [24]. This novel reinforcing strategy irrespective of the great polarity discrepancy between polar lignin and non-polar SBR is highly desirable. The formation and characteristics of lignin-F51 networks were investigated. The mechanical performances and vulcanization behaviors were studied as well as the thermal stability.

\section{Materials and methods}

\subsection{Materials}

Industrial sulfate lignin (the average molecular weight is 4235 and the polydispersity index is 2.4 ) was kindly provided by Guangzhou Linge Polymer Material Co., Ltd. (China). SBR latex with trade name of SBR 132 (the solid contents of the latex was $65 \mathrm{wt} \%$ ) was obtained from Dongguan Benke Latex Co., Ltd. (China), which is a random copolymer consisting of $25 \mathrm{wt} \%$ styrene monomer. Novolac epoxy resin (tradename F51, which is a low molecular weight liquid) was purchased from Nanya Plastics Corporation (the epoxy value is 0.51 ) in China. The structures of the materials are given in Figure 1. The reagents used in rubber formula such as zinc oxide (ZnO), Stearic acid (SA), Sulfur (S), Accelerator N-

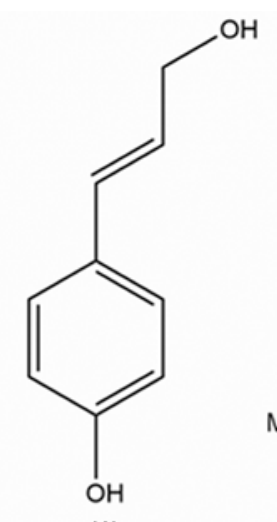

(1)

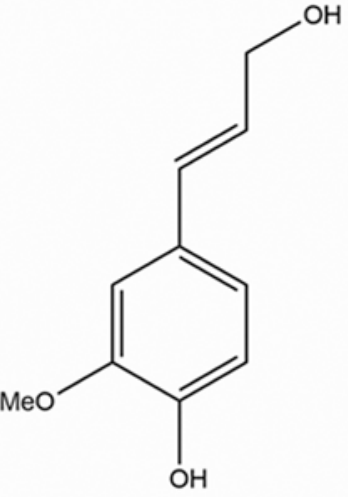

(2)

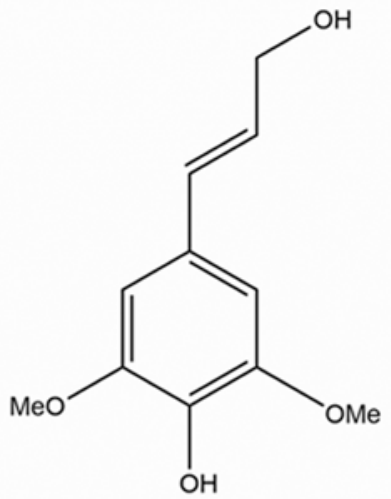

(3)

Lignin building blocks: (1) paracoumaryl alcohol, (2) coniferyl alcohol and (3) sinapyl alcohol

Novolac epoxy resin

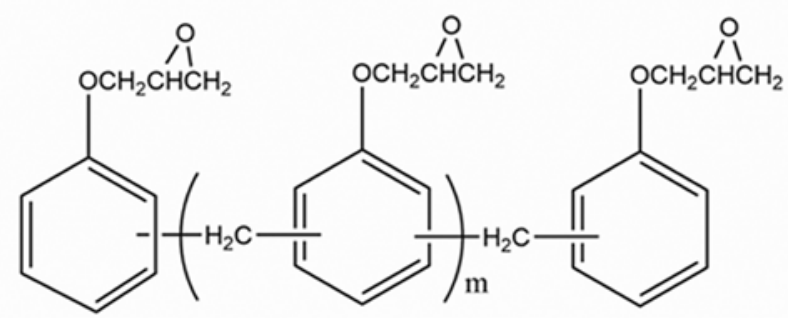

Figure 1. Structures of raw materials 
cyclohexyl-2-benzothiazole sulfonamide (CZ) and Accelerator 2,2'-dibenzothiazole disulfide (DM) were provided by Rubber Institute of Guangzhou in China.

\subsection{Preparation of $\mathrm{SBR} / \mathbf{5 0 l i g n i n}$ compounds}

Lignin was dissolved in deionized water at a mass concentration of $10 \%$ and the $\mathrm{pH}$ was adjusted to 12.5. The lignin solution (the dry weight ratio of lignin to SBR is $1: 2$ ) was dropped slowly into the SBR latex with vigorous stirring, and then $5 \mathrm{wt} \%$ sulfuric acid solution was added to co-coagulate the mixture. The mixture was filtered, water washed and then dried in oven at $70^{\circ} \mathrm{C}$ until a constant weight was obtained, the compounds were named SBR/50lignin.

\subsection{Preparation of SBR/50lignin/F51 compounds and SBR/F51 compounds}

F51 was added in the SBR/50lignin (or SBR) compounds by using a two-roll mill, followed by adding zinc oxide, stearic acid, accelerator $\mathrm{CZ}$, accelerator $\mathrm{DM}$ and sulfur according to the recipe listed in Table 1. The compounds were compression molded and vulcanized at $160^{\circ} \mathrm{C}$ for optimum vulcanization time $\left(T_{90}\right)$, which was determined by the U-CAN UR-2030 vulcameter. The preparation of SBR/
50lignin/F51 compounds is schematically depicted in Figure 2. The compounds were named SBR/ 50 lignin $/ x \mathrm{~F} 51$ or $\mathrm{SBR} / x \mathrm{~F} 51$ compounds, $x$ refers to the phr of F51 in the compounds (phr refers to parts per hundred of rubber).

\subsection{Preparation of Model Compounds}

In order to explore the possible interactions between lignin and F51, two model compounds were designed.

Model Compounds A: $100 \mathrm{~g}$ lignin and $20 \mathrm{~g}$ F51 were mixed in the high-speed multi mill (the speed was $30000 \mathrm{rpm}$ ) for 5 minute, then put it in the oven for a curing process at the $160^{\circ} \mathrm{C}$ for $30 \mathrm{~min}$ utes. Fourier-transform infrared (FTIR) spectroscopy was used to characterize the possible reactions between lignin and F51 before and after curing. For comparison, neat lignin and neat F51 were also studied by FTIR.

Model Compounds B: $N$-SBR/50lignin/F51 compounds were prepared with the same procedure of SBR/50lignin/F51 except that no rubber additives (sulfur etc.) were added. For comparison, $N$-SBR and $N$-SBR/20F51 were also prepared. Note that $N$ means that no rubber additives were added in this paper.

Table 1. Formulation of the mixtures and purposes*

\begin{tabular}{|l|l|}
\hline \multicolumn{1}{|c|}{ Samples } & \multicolumn{1}{|c|}{ Purpose } \\
\hline SBR, SBR/5F51, SBR/10F51, SBR/15F51, SBR/20F51. & To determine the influence of F51 on curing behavior of SBR vulcanizates. \\
\hline $\begin{array}{l}\text { SBR/50lignin, SBR/50lignin/5F51, SBR/50lignin/10F51, } \\
\text { SBR/50lignin/15F51, SBR/50lignin/20F51. }\end{array}$ & To determine the influence of F51 on SBR/50lignin vulcanizates. \\
\hline
\end{tabular}

*rubber ingredients: ZnO 5, Stearic acid 2, S 1.6, Accelerator CZ 1.5, Accelerator DM 0.5.

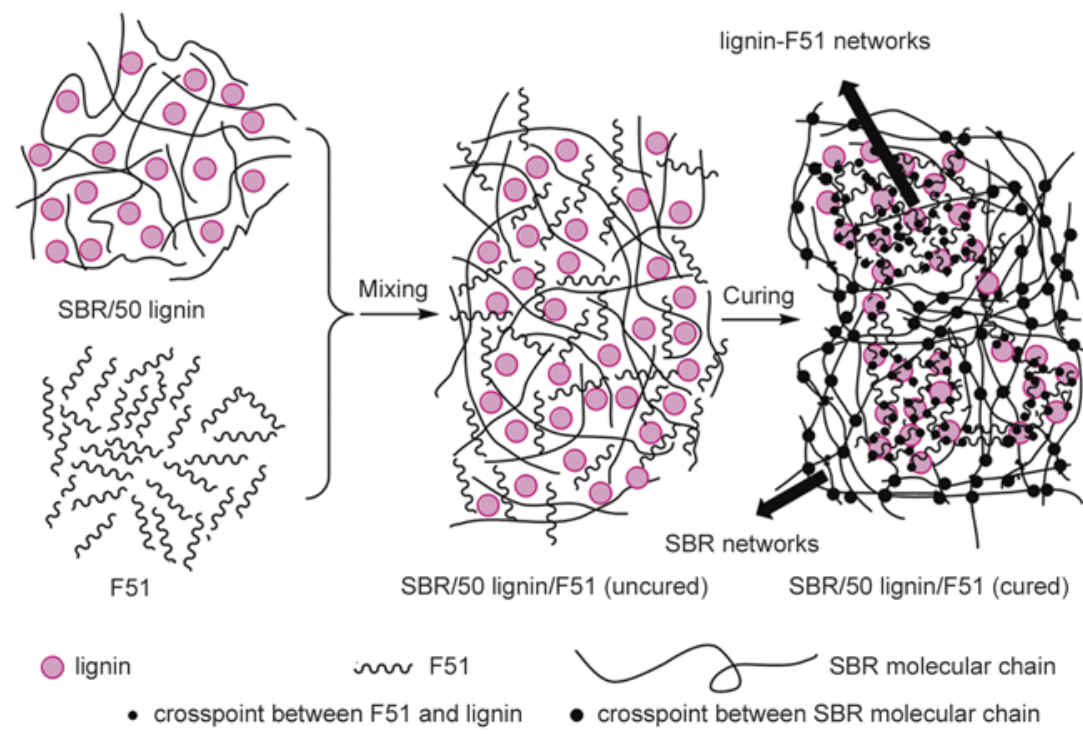

Figure 2. The preparation of SBR/50lignin/F51 


\subsection{Characterizations}

Fourier transform infrared spectra (FTIR) were recorded in transmission mode on a Bruker Vertex 70 infrared spectrum analyzer (BRUKER OPTICS, Germany) with $\mathrm{KBr}$ pellets within the wave number range from 4000 to $400 \mathrm{~cm}^{-1}$. The scanning was performed 32 times with a resolution of $4 \mathrm{~cm}^{-1}$.

Mechanical properties measurements. The tensile and tear tests of the vulcanizates were performed according to ASTM D412 and ASTM D624 specifications, respectively. U-CAN UT-2060 (U-CAN Dynatex Inc., Taiwan) instrument was used with the strain rate of $500 \mathrm{~mm} / \mathrm{min}$.

The curing characteristics of the compounds were determined at $160^{\circ} \mathrm{C}$ by U-CAN UR-2030 vulcameter (U-CAN Dynatex Inc., Taiwan).

Dynamic mechanical analysis was conducted on a Netzsch 242C DMA equipment (Netzsch, Germany). The tensile mode was selected. The measurements were carried out at a frequency of $2 \mathrm{~Hz}$, a heating rate of $5^{\circ} \mathrm{C} / \mathrm{min}$ over a temperature range of -90 to $200^{\circ} \mathrm{C}$.

Measurements of crosslink density were carried out on Magnetism Resonance crosslinking density spectrometer (XLDS-15, IIC Innovative Imaging Corporation, Germany) according to the IIC test and analysis software package with a magnetic field intensity of $15 \mathrm{MHz}$ at $85^{\circ} \mathrm{C}$. Rubber sample with a length of $10 \mathrm{~mm}$ and a diameter of approximately $6 \mathrm{~mm}$ was placed into a glass tube for the test.

Thermal gravimetric analysis was carried out in a TA Q20 (TA Corporation, New Castle, America) thermogravimetric analyzer over a temperature range from 30 to $700^{\circ} \mathrm{C}$ at a heating rate of $10^{\circ} \mathrm{C} / \mathrm{min}$. Nitrogen was used as purging gas.

Rubber process analysis (RPA) was carried out in a RPA2000 (Alpha technologies Co, USA). Strain sweeps of uncured composites: During the strain sweeps, the temperature and frequency were kept at $60^{\circ} \mathrm{C}$ and $60 \mathrm{cpm}$, respectively. The range of the strain sweeps was $0-200 \%$. Storage modulus $\left(G^{\prime}\right)$ was measured as a function of strain. Strain sweeps of cured composites: the temperature was raised to $160^{\circ} \mathrm{C}$ to cure the compound for $T_{90}$. Then, the temperature was reduced to $60^{\circ} \mathrm{C}$ again. During the strain sweeps, the temperature and frequency were kept at $60^{\circ} \mathrm{C}$ and $60 \mathrm{cpm}$. The range of the strain sweeps was 0-140\% for the vulcanizates.

Scanning electron micrographs (SEM) of the composites were taken by a Nova Nano SEM 430 instrument (FEI, Netherlands), the voltage of the electron beam used for SEM observation was $10 \mathrm{kV}$. Preparation of the tensile fracture surface: the tensile fracture surfaces of SBR/50lignin and SBR/50lignin/ 20F51 were obtained by the tensile tests. Preparation of the etched surfaces of $N-\mathrm{SBR} / 50$ lignin/F51: $N$-SBR/50lignin/F51 compounds were fractured at liquid $\mathrm{N}_{2}$ temperature and then etched by toluene for 10 days to remove the free SBR matrix (the SBR phase are not crosslinked since no sulfur was added), then the etched surfaces were obtained. Note that all the samples were plated with a thin layer of gold before any observations.

\section{Results and discussion}

\subsection{Reactions between lignin and F51}

In the present study, it is believed that the $\mathrm{OH}$ groups (or $\mathrm{COOH}$ groups) of lignin could react with the epoxy groups of F51 by the ring-opening reaction, the reaction between $\mathrm{OH}$ and epoxy groups is schematically illustrated in Figure 3.

In order to eliminate the disturbance of SBR molecules in the FTIR investigation, the FTIR of F51/ lignin $=5: 1$ (uncured and cured), F51 and lignin were performed and the results are presented in Figure 4 . In the spectrum of lignin, the broad strong band between 3700 and $3200 \mathrm{~cm}^{-1}$ belongs to the hydroxyl stretching vibrations of lignin hydroxyls or absorbed water, and the peaks at about 2935 and $1460 \mathrm{~cm}^{-1}$ are attributed to $\mathrm{CH}$ stretching of methyl $\left(\mathrm{CH}_{2}\right)$ or methylene groups $\left(\mathrm{CH}_{3}\right)$. The absorption at about $1700 \mathrm{~cm}^{-1}$ are attributed to $\mathrm{C}=\mathrm{O}$ stretching

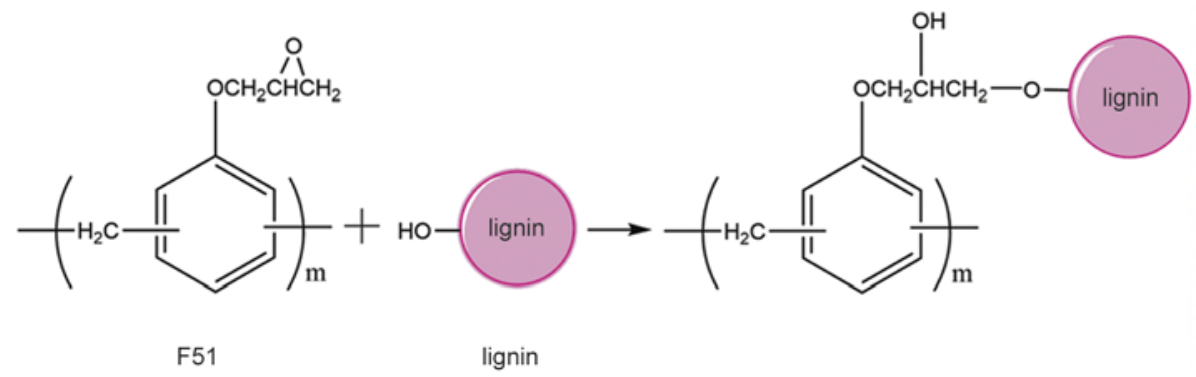

Figure 3. Schematic of the reaction between the epoxy groups of F51 and $\mathrm{OH}$ groups of lignin 


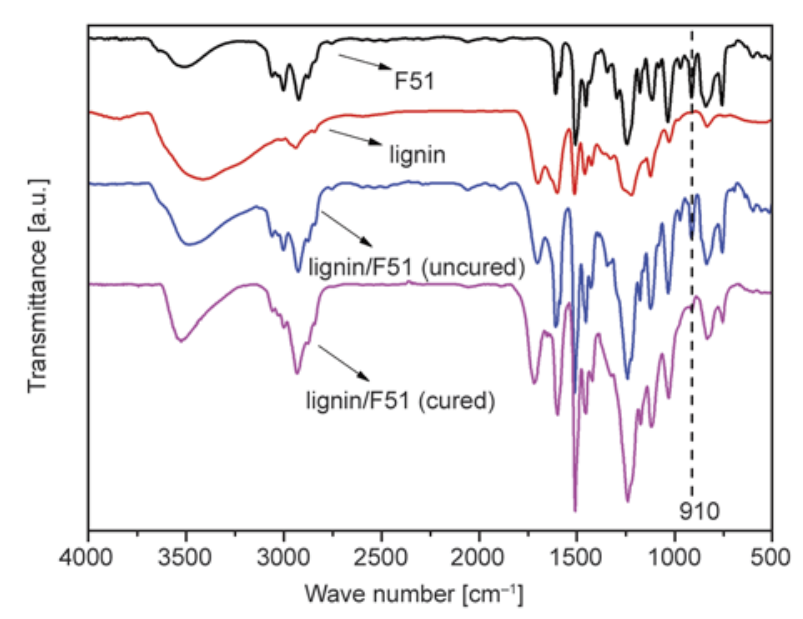

Figure 4. FTIR spectra of Model Compounds A

of lignin, and the absorption at 1510, 1424 and $1600 \mathrm{~cm}^{-1}$ is assigned to the aromatic skeletal vibration. Compared to lignin, in the case of uncured F51/lignin, there are some new absorption peaks appeared, and the peaks at $910 \mathrm{~cm}^{-1}$ are assigned to the stretching vibration of the $\mathrm{C}-\mathrm{O}$ of the epoxy, which belong to characteristic absorptions of F51. This band almost disappeared after curing, indicating that F51 could react with lignin via the ringopening reaction under the curing process of $160^{\circ} \mathrm{C}$. Curing analysis of Model Compounds B were carried out to characterize the possible interactions between lignin and F51. As shown in Figure 5, the maximum torque $\left(M_{\mathrm{H}}\right)$ of $N$-SBR/20F51 is lower than that of $N$-SBR, this is because that F51 remains a low molecular weight liquid which acts as a plasticizer and lubricant in the SBR/20F51. Indicating there are no crosslinking reaction between F51 and $\mathrm{SBR}$. The $M_{\mathrm{H}}$ of $N$-SBR/50lignin is higher than that

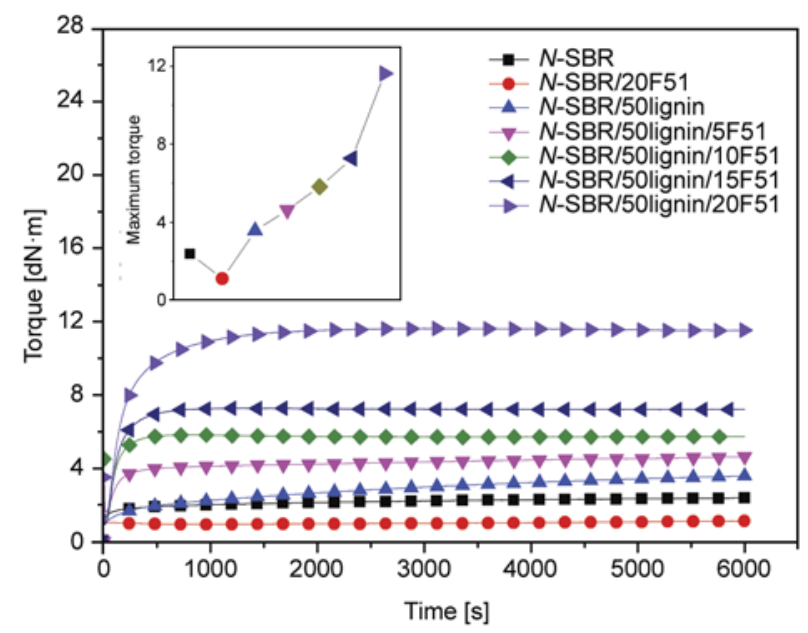

Figure 5. Curing curves of the Model Compounds B at $160^{\circ} \mathrm{C}$ of $N$-SBR, this is because that there will be the rubber-filler interaction as well as usual volume fraction effects after addition of lignin, and this tends to impose extra resistance to flow of the SBR composites as a higher restriction to motion of the SBR molecules [25]. The $M_{\mathrm{H}}$ of $N$-SBR/50lignin/F51 compounds increases significantly with the increasing loading of F51. As an increase in torque is proportional to the crosslinking density [18]. It is evident that the crosslinked networks are formed due to the crosslinking reactions between lignin and F51. In order to further substantiate the formation and existence of lignin-F51 networks in the composites, the etched surfaces of $N$-SBR/50lignin/F51 are observed by SEM. As shown in Figure 6, no networks are observed in the sample of $N$-SBR/ 50lignin. However, preliminary networks embedded in the matrix are observed which disperse uniformly in the sample of $\mathrm{N}$-SBR/50lignin/5F51, and the network pores are approximately 200 500 nanometers. In the sample of SBR/50lignin/10F51, the morphologies of the networks resemble glass fibers, the networks become more obvious and the network pores become smaller. In the sample of SBR/ 50lignin/15F51, irregular spherical particles are formed and interconnected. It should be noted that the lignin-F51 networks are not exactly the identical with the networks observed in Figure 6, this is because if a rubber and a filler are mixed, they interact in such a way that even a good solvent can only partially dissolve the rubber which originally is completely soluble in the solvent. The insoluble rubber is often referred to as the bound rubber [26]. We can infer that the networks observed in Figure 6 is complex of lignin-F51 networks and bound rubber held together by lignin-F51 networks. Since the networks observed in Figure 6 is closely related with lignin-F51 networks, we can say that the general morphology of F51-lignin networks is roughly outlined in the SEM when the free SBR was dissolved by toluene. So we demonstrate the existence of lignin-F51 network.

\subsection{Curing analysis of $\mathrm{SBR} / 50$ lignin/F51 compounds and SBR/F51 compounds}

As shown in Figure 7 and Table 2, the $T_{90}$ of SBR/ F51 compounds is increased significantly with the increasing loading of F51, indicating that F51 delays the vulcanization, which is ascribed to the consumption of rubber additives by epoxy group of 

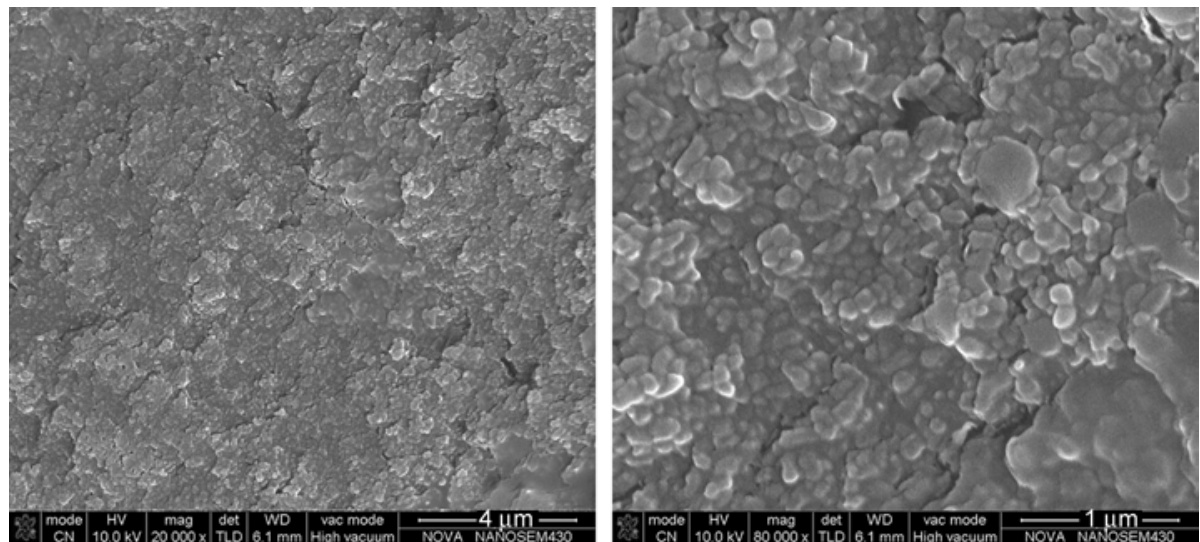

a) $20000 x$

$80000 x$
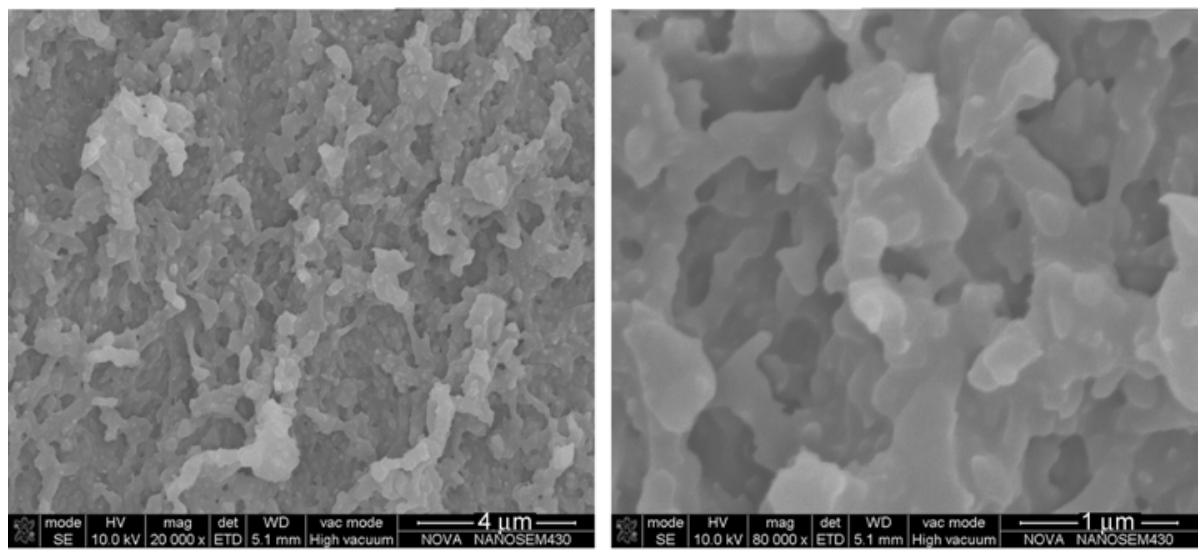

b) $20000 x$

$80000 x$

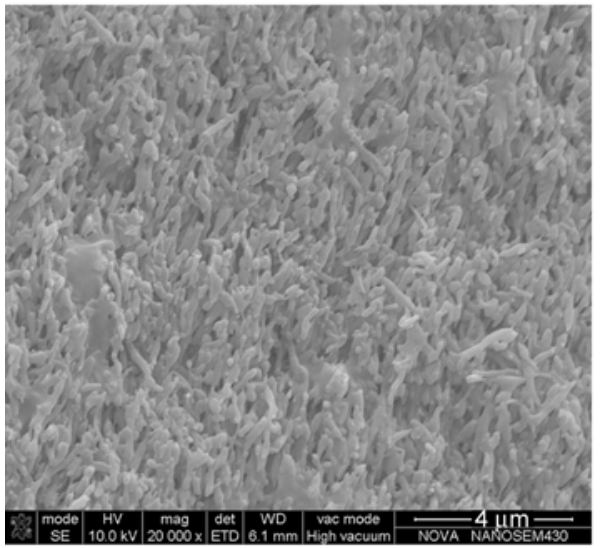

c) $20000 x$
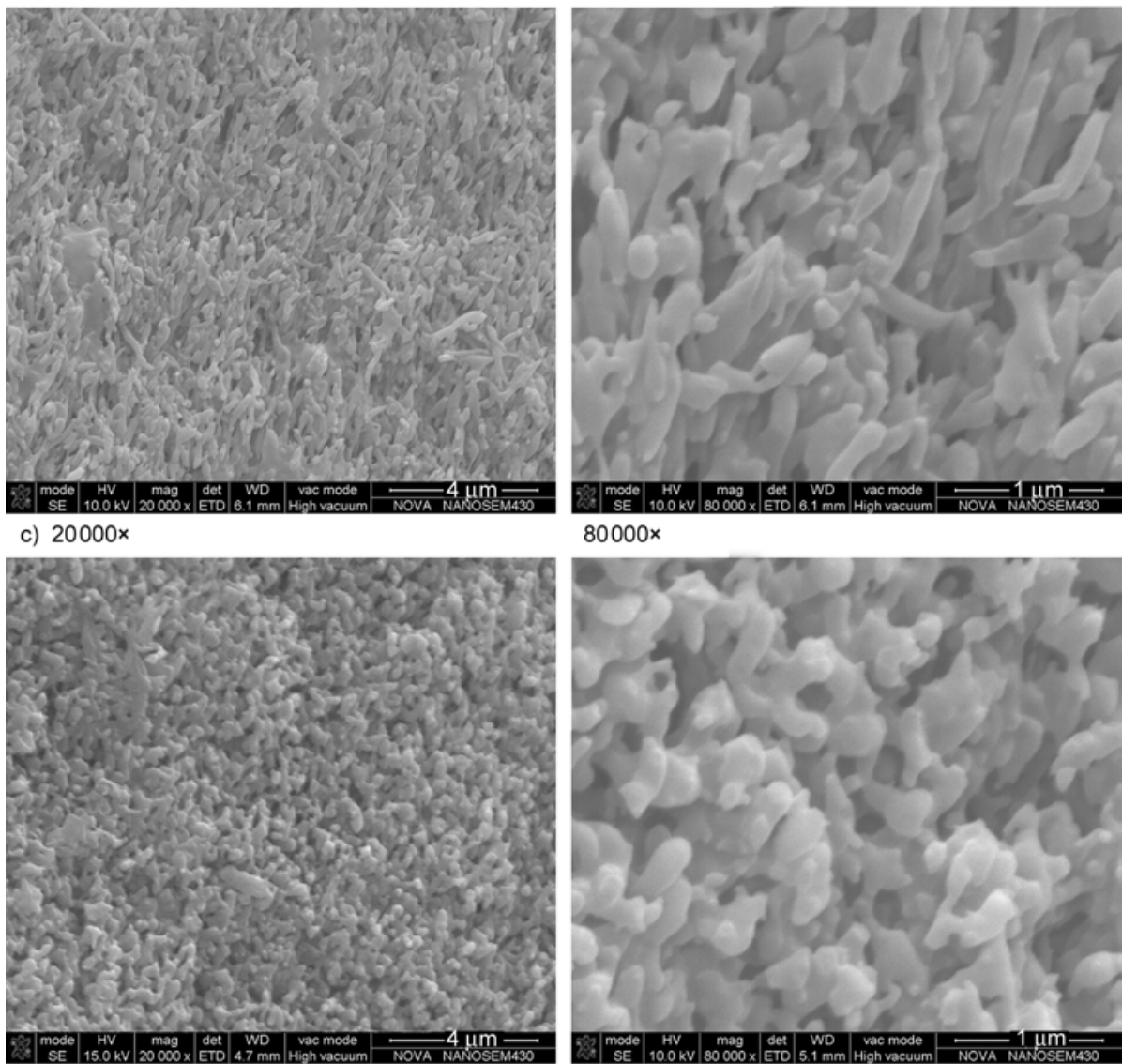

d) $20000 x$

$80000 x$

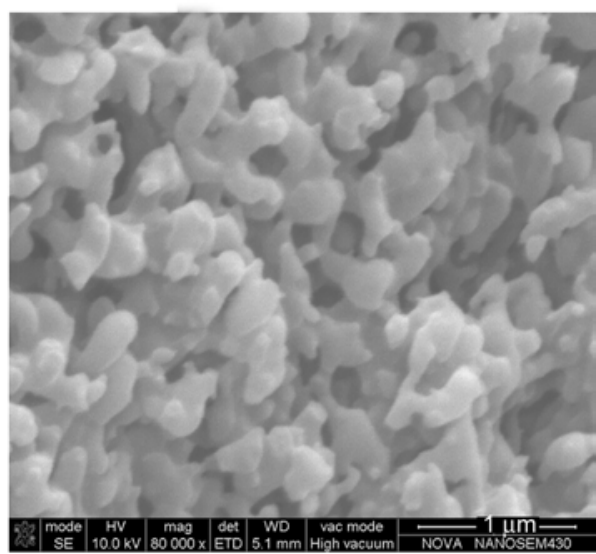

$80000 x$

Figure 6. SEM images of the samples etched by toluene (a) $N$-SBR/50lignin, (b) $N$-SBR/50lignin $/ 5 \mathrm{~F} 51$, (c) $N$ SBR/50lignin/10F51, (d) $N$-SBR/50lignin/15F51 


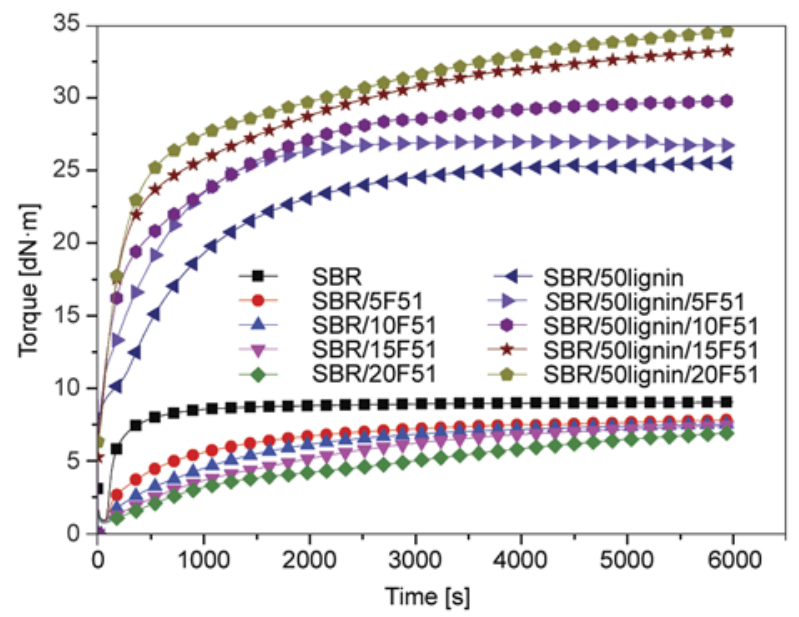

Figure 7. Curing curves of the SBR/F51 and SBR/50lignin/ F51 compounds at $160^{\circ} \mathrm{C}$

Table 2. Curing parameters of the rubber compounds $\left(160^{\circ} \mathrm{C}\right)^{*}$

\begin{tabular}{|l|r|c|c|c|c|}
\hline \multicolumn{1}{|c|}{ Samples } & $\begin{array}{c}\mathbf{T}_{\mathbf{S 2}} \\
{[\mathbf{m i n}]}\end{array}$ & $\begin{array}{c}\mathbf{T}_{\mathbf{9 0}} \\
{[\mathbf{m i n}]}\end{array}$ & $\begin{array}{c}\mathbf{M}_{\mathbf{L}} \\
{[\mathbf{d N} \cdot \mathbf{m}]}\end{array}$ & $\begin{array}{c}\mathbf{M}_{\mathbf{H}} \\
{[\mathbf{d N} \cdot \mathbf{m}]}\end{array}$ & $\begin{array}{c}\mathbf{\Delta M} \\
{[\mathbf{d N} \cdot \mathbf{m}]}\end{array}$ \\
\hline SBR & 1.50 & 11.18 & 0.9. & 9.03 & 8.13 \\
\hline SBR/5F51 & 3.26 & 46.28 & 0.85 & 7.81 & 6.96 \\
\hline SBR/10F51 & 7.03 & 51.12 & 0.84 & 7.53 & 6.69 \\
\hline SBR/15F51 & 10.32 & 66.06 & 0.76 & 7.44 & 6.68 \\
\hline SBR/20F51 & 12.52 & 78.30 & 0.70 & 6.93 & 6.20 \\
\hline SBR/50lignin & 3.00 & 39.54 & 8.15 & 25.57 & 17.42 \\
\hline SBR/50lignin/5F51 & 0.44 & 22.42 & 7.92 & 27.02 & 19.10 \\
\hline SBR/50lignin/10F51 & 0.48 & 36.37 & 7.48 & 29.84 & 22.36 \\
\hline SBR/50lignin/15F51 & 0.45 & 48.58 & 7.24 & 33.30 & 26.06 \\
\hline SBR/50lignin/20F51 & 0.43 & 52.37 & 6.49 & 34.64 & 28.15 \\
\hline
\end{tabular}

$M_{\mathrm{L}}$ : the minimum torque; $M_{\mathrm{H}}$ : the maximum torque; $\Delta M$ : the difference between maximum torque and minimum torque; $T_{\mathrm{S} 2}$ : scorch time; $T_{90}$ : optimum cure time.

F51 [27]. The $T_{90}$ of SBR and SBR/50lignin is 11.18 and $39.54 \mathrm{~min}$ respectively, indicating that incorporation of lignin in rubber matrix delays the vulcanization of rubber matrix, which is ascribed to the adsorption between lignin and vulcanization additives [14]. Compared to SBR/50lignin, the scorch time of SBR/50lignin/F51 are reduced, which is attributed to the reaction between lignin and F51. However, with the increasing loading of F51, $T_{90}$ of $\mathrm{SBR} / 50$ lignin/F51 is initially decreased. When the F51 content is higher than $5 \mathrm{phr}, T_{90}$ starts to rise. There are three factors regulating the values of $T_{90}$ of SBR/50lignin/F51 compounds. Firstly, the interactions between F51 and lignin actually act as efficient crosslinks in the vulcanizates, resulting in accelerated vulcanization [28]. Secondly, F51 reacts with lignin which would adsorb vulcanization additives, and this two effects tend to promote the vulcanization. Thirdly, F51 consumed rubber additives as mentioned above. This effect tends to delay the vulcanization. When the F51 content is relatively low $(5 \mathrm{phr})$, the first and second effects play the leading role, resulting in accelerated curing behavior. When the F51 content is high enough (exceeding $5 \mathrm{phr}$ ), the consumption of the rubber additives by F51 plays the leading role, resulting in delayed curing behavior. The $M_{\mathrm{H}}$ of the SBR/50lignin/F51 is increased with F51 loading, suggesting more F51, more crosslinks between lignin and F51. While the $M_{\mathrm{L}}$ (the minimum torque) of the SBR/50lignin/ F51 is decreased with F51 loading, and this is related to the fact that the F51 acts as a lubrication agent and plasticizer in the rubber compound. As it is known, a relatively low $M_{\mathrm{L}}$ suggested superior flow ability [29]. Therefore it could be concluded that the inclusion of F51 leads to a better processability.

\subsection{RPA analysis results}

RPA was used to analyze the dynamic viscoelastic properties of SBR/50lignin/F51 composites before and after curing. As shown in Figure 8, it is found that the modulus decreases dramatically with the increase of strain amplitude for all compounds, and this was because filler networks will be destroyed when the strain reaches a high amplitude, and the Storage modulus $\left(G^{\prime}\right)$ of all compounds drops to almost the same low-value. This can be explained by the Payne effect [30]. As shown in Figure 8a, the initial modulus of SBR/50lignin uncured compound is higher than that of those uncured compounds adding F51. Moreover, with the increase of F51, the initial modulus of the compounds decreases, and this was because the F51 molecules act as plasticizers and lubricants. This is similar to the article of He et al. [31] that filler network interaction in $\mathrm{SBR} /$ rectorite was reduced by adding glycerin or aromatic oil. It indicates that adding F51 could weaken the filler network interaction and reduce the Payne effect, and then enhances the processability of the compounds.

As shown in Figure 8b, in vulcanized compounds, the values of $G^{\prime}$ are significantly higher than that of uncured material, this is due to formation of ligninF51 networks and the crosslinked SBR networks after curing process and the networks restricting the mobility of rubber chains. The $G^{\prime}$ of the compounds increase with the loading of F51, and this can be ascribed to that more F51 lead to a stronger ligninF51 networks and higher crosslink density, which 


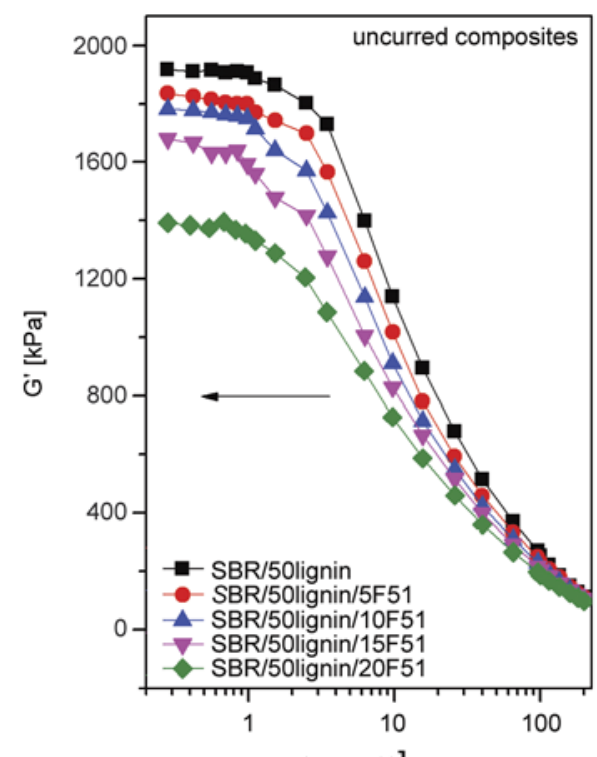

a)

$$
\text { Strain [\%] }
$$

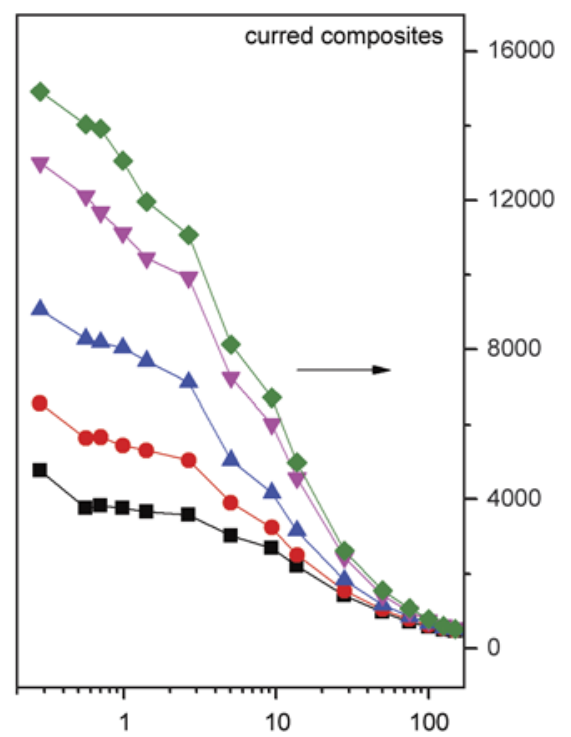

Strain [\%]

Figure 8. Storage modulus ( $G^{\prime}$ )-strain sweeps: (a) the uncured and (b) cured SBR/50lignin/F51 composites

further promote restriction on the mobility of rubber chains, indicating that the formation of the ligninF51 networks have a significant reinforcement.

\subsection{DMA analysis results}

The dynamic mechanical properties of the SBR/ 50lignin/F51 composites were characterized by DMA. As shown in Figure 9a, there is an increase in storage modulus $\left(E^{\prime}\right)$ after incorporation of F51, which can be attributed to the formation of strong lignin-F51 networks and the networks have a significant restriction on SBR matrix. $E^{\prime}$ is widely accepted as directly proportional to the degree of elasticity, which correlates well with crosslink density [30], and this is in accordance with our findings below.

As shown in Figure 9b. DMA studies reveal that the SBR/lignin/F51 composites exhibit two glass tran-

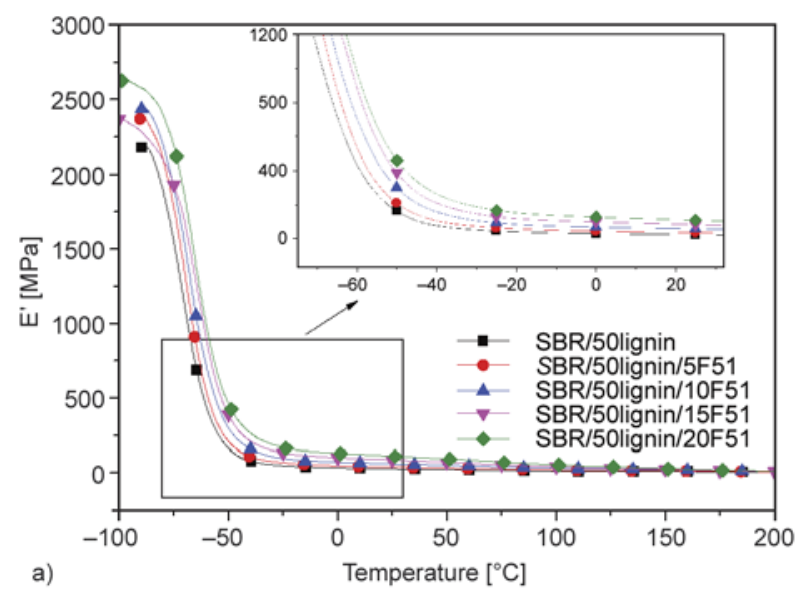

sition temperature: one occurring at low temperature $\left(T_{\mathrm{g} 1}\right)$ is associated to SBR and the second at high temperature $\left(T_{\mathrm{g} 2}\right)$ corresponds to the ligninF51 networks. The $T_{\mathrm{g} 1}$ of SBR is shifted from -56.63 to $-55.15^{\circ} \mathrm{C}$ with increasing loading of $\mathrm{F} 51$ from 0 to 20 phr. Furthermore, it can be observed that the tan peak values and half-peak width of $T_{\mathrm{g} 1}$ are decreased with the increase of F51 content, suggesting continuously decrease in rubber chain mobility [24, 32], and this is due to the strong interaction between the rigid lignin-F51 network and SBR matrix. There is an evident $T_{\mathrm{g} 2}$ after incorporation of F51 at a level above $5 \mathrm{phr}$, and the tan peak of $T_{\mathrm{g} 2}$ become increasingly obvious with the increasing loading of F51. It is logical to conclude that the $T_{\mathrm{g} 2}$ is the glass transition temperature of lignin-F51 $[33,34]$. The emergence of $T_{\mathrm{g} 2}$ further substantiate the existence of the F51-lignin networks.

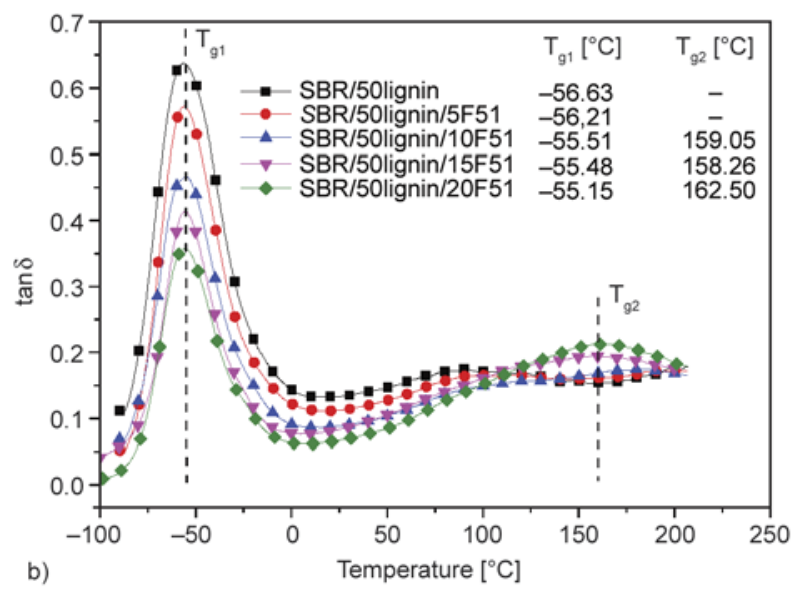

Figure 9. Storage modulus $E^{\prime}$ (a) and $\tan \delta$ (b) of SBR/50lignin/F51 


\subsection{TGA analysis results}

Figure 10 illustrates the TG and DTG curves of SBR/ 50lignin/F51 with different F51 loading respectively. Table 3 shows the thermal degradation characteristics of the composites. The thermal degradation behavior of all SBR/50lignin/F51 composites with one main mass loss step are similar. A notable shift of 5, 10\% weight loss to higher temperature can be observed with the loading of F51. For instance, the $T_{5 \%}$ and $T_{10 \%}$ of SBR/50lignin/20F51 is 274.7 and $336.0^{\circ} \mathrm{C}$, which are about 25 and $10^{\circ} \mathrm{C}$ higher than those of SBR/50lignin, and this is attributed to the introduction of novolac epoxy resin with high concentrations of aromatic rings which can improve thermal stability [35] and lignin-F51 networks hindering the diffusion of small molecules generated during the thermal decomposition. Besides, to some extent the improvement of the crosslinking density can promote the thermal stability. However, the peak degradation temperature $\left(T_{\max }\right)$ of $\mathrm{SBR} /$ 50lignin/F51 is slightly lower than the $T_{\max }$ of SBR/ 50lignin, which is attributed to the possibility of the epoxy resins decomposition at higher temperature.

Table 3. Thermal degradation characteristics of the rubber compounds*

\begin{tabular}{|l|c|c|c|c|}
\hline \multicolumn{1}{|c|}{ Samples } & $\begin{array}{c}\mathbf{T}_{\mathbf{5} \%} \\
{\left[{ }^{\circ} \mathbf{C}\right]}\end{array}$ & $\begin{array}{c}\mathbf{T}_{\mathbf{1 0}}{ }^{\circ} \\
{\left[{ }^{\circ} \mathbf{C}\right]}\end{array}$ & $\begin{array}{c}\mathbf{T}_{\mathbf{m a x}} \\
{\left[{ }^{\circ} \mathbf{C}\right]}\end{array}$ & $\begin{array}{c}\text { Residue at } \mathbf{7 0 0}^{\circ} \mathbf{C} \\
{[\mathbf{\%}]}\end{array}$ \\
\hline SBR/50lignin & 249.4 & 325.4 & 456.9 & 14.2 \\
\hline SBR/50lignin/5F51 & 253.6 & 328.1 & 456.1 & 14.2 \\
\hline SBR/50lignin/10F51 & 265.6 & 334.1 & 455.9 & 14.8 \\
\hline SBR/50lignin/15F51 & 268.6 & 334.3 & 453.2 & 14.2 \\
\hline SBR/50lignin/20F51 & 274.7 & 336.0 & 453.4 & 14.9 \\
\hline
\end{tabular}

${ }^{*} T_{5 \%}-5 \%$ weight loss temperature. $T_{10 \%}-10 \%$ weight loss temperature. $T_{\max }-$ the peak degradation temperature.

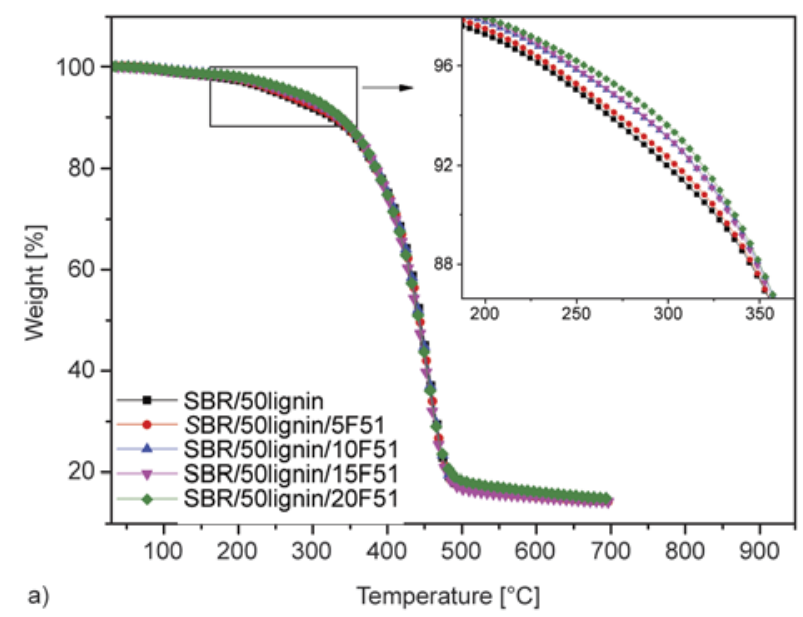

\subsection{Crosslink density analysis}

Recently, many researchers use Magnetic Resonance Crosslink Density Measurements to the determinate the crosslink densities in rubber materials [36-39], and not only this method simple to use and time-saving but also this method can provide several more parameters characterizing the molecular dynamics of the network. Such as the average molecular weight of chains between two adjacent crosslinks $\left(M_{\mathrm{c}}\right)$, the motion of dangling chain ends and free chain $\left(A\left(T_{2}\right)\right)$, and the percentage of inter crosslink chain $A\left(M_{\mathrm{c}}\right)$, etc. $A\left(T_{2}\right)$ represents the percentage of high-mobile fractions while $A\left(M_{\mathrm{c}}\right)$ represents percentage of crosslinking fractions [40]. A less Crosslink Density value usually corresponds to a bigger $M_{\mathrm{c}}$ value $[38,41]$ and a less $A\left(T_{2}\right)$ value usually corresponds to a bigger $A\left(M_{\mathrm{c}}\right)$ value [38]. The network structure characterization of vulcanizate with Magnetic Resonance Crosslink Density Measurements is described in detail in the references [42-44]. The results of crosslinking density are shown in Table 4, it is shown that the crosslink density of SBR vulcanize is higher than that of SBR/50lignin, this is because that there are abundant acidic $\mathrm{OH}$ in lignin since acidic agents have an adverse effect on the vulcanization of the rubber [36]. The $A\left(T_{2}\right)$ of SBR vulcanize is higher than that of SBR/50lignin. This is because that the addition of lignin could impose extra restriction to the mobility of the SBR and reduce the proportion of activity units. Compared to SBR/50lignin, the crosslink density of SBR/50lignin/F51 shows an increasing trend with the increase of F51, owing to the crosslink reaction between F51 and lignin. As the

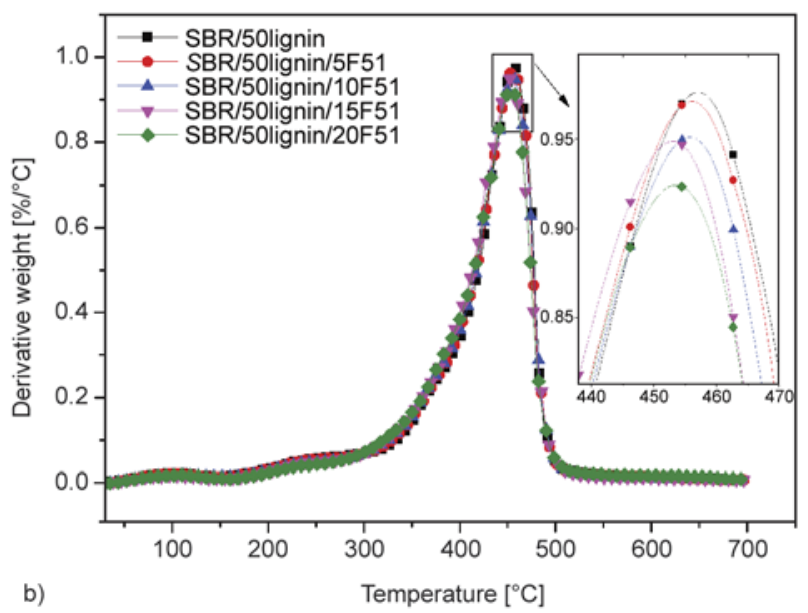

Figure 10. TGA curves (a) and DTG curves (b) of SBR/50lignin/F51 
Table 4. Crosslink density of SBR/50lignin/F51 compounds*

\begin{tabular}{|l|r|r|c|c|c|c|}
\hline \multirow{2}{*}{\multicolumn{1}{|c|}{ Properties }} & \multicolumn{7}{c|}{ Samples(SBR/lignin/F51) } \\
\cline { 2 - 7 } & $\mathbf{1 0 0 / 0 / 0}$ & $\mathbf{1 0 0 / 5 0 / 0}$ & $\mathbf{1 0 0 / 5 0 / 5}$ & $\mathbf{1 0 0 / 5 0 / 1 0}$ & $\mathbf{1 0 0 / 5 0 / 1 5}$ & $\mathbf{1 0 0 / 5 0 / 2 0}$ \\
\hline $\mathrm{XLD}\left[10^{-5} \mathrm{~mol} / \mathrm{cm}^{3}\right]$ & 9.33 & 9.18 & 9.35 & 9.43 & 9.69 & 10.15 \\
\hline$M c[\mathrm{~K} \cdot \mathrm{g} / \mathrm{mol}]$ & 10.18 & 10.35 & 10.16 & 10.07 & 9.80 & 9.36 \\
\hline$A(M c)[\%]$ & 53.06 & 57.58 & 62.01 & 62.94 & 68.12 & 68.21 \\
\hline$A\left(T_{2}\right)[\%]$ & 46.33 & 40.60 & 37.02 & 35.03 & 32.90 & 31.59 \\
\hline
\end{tabular}

${ }^{*}$ XLD: crosslinking density; $M c$ : the average molecular weight between two crosslinking point; $A(M c)$ : the motion of inter crosslink chain; $A\left(T_{2}\right)$ : the motion of dangling chain ends and free chain.

integrity of crosslink network was improved, $A\left(M_{\mathrm{c}}\right)$ increased and $A\left(T_{2}\right)$ decreased [38]. This result shows that the formation of lignin-F51 networks can bring on more crosslinking points, fewer activity units, and lower activity ability. The crosslink density results of SBR/50lignin/F51 is consistent with the maximum torque of curing test, Shore A hardness and tensile modulus.

\subsection{Mechanical properties}

As shown in Figure 11 and Table 5. It can be observed that the tensile strength of SBR and SBR/ 10F51 are very poor, indicating that F51 alone shows almost no reinforcing effect. It could be seen that the tear strength, 300\% modulus and Shore A hardness of the SBR/50lignin/F51 composites increase with the increase of F51, for instance, the tear strength and $300 \%$ modulus are increased from $49.4 \mathrm{kN} / \mathrm{m}$,

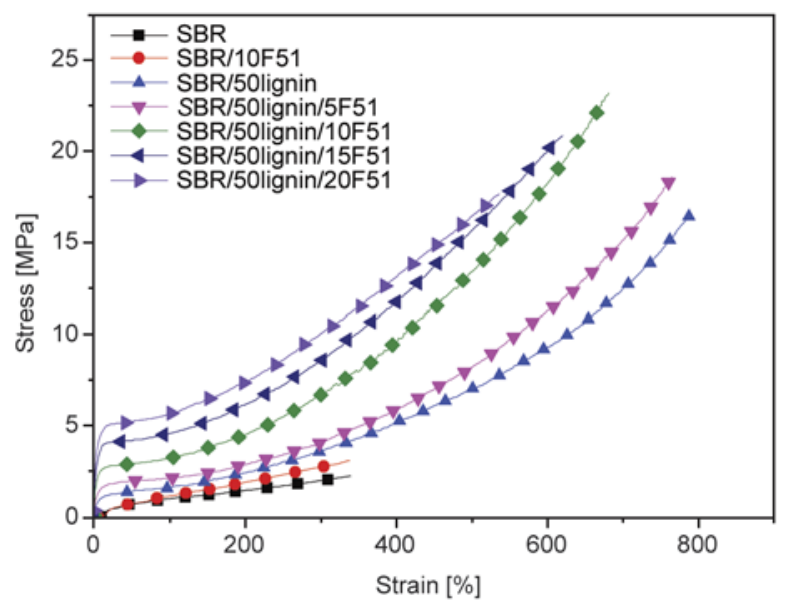

Figure 11. Stress-strain curve of the rubber composites
3.6 MPa of SBR/50lignin to $62.2 \mathrm{kN} / \mathrm{m}$ and $10.0 \mathrm{MPa}$, respectively, when $20 \mathrm{phr}$ F51 is added. This is because the stress will transfer from SBR molecular chains to the lignin-F51 networks effectively before a catastrophic breakage happens, which demonstrates the good reinforcement by the rigid lignin-F51 network. However, the elongation at break of SBR/50lignin/F51 decreases with the increase of F51 content. This is because the ligninF51 networks decrease the deformation resistance of rubber chains. Additionally, the strong interactions between the rigid lignin-F51 networks and SBR matrix can prevent the recovery of the rubber molecular chains after deformation, resulting in the increased permanent set.

As shown in Figure 12, the tensile fracture surface of SBR/50lignin and SBR/50lignin/20F51 are observed by SEM. It should be noted that the sample of SBR/50lignin/20F51 exhibits much more rugged fracture surfaces than those of SBR/50lignin, indicating that the lignin-F51 networks can bear more external force when an exerted stress is applied to the matrix. This investigation has demonstrated that lignin-F51 networks could be an effective route for the enhancement of SBR.

\section{Conclusions}

A novel reinforcing strategy for SBR via the ligninF51 networks in the SBR matrix is proposed. The F51 can form covalent bonds with lignin via the ringopening reaction between F51 and lignin, which is substantiated by the results of FTIR. The existence

Table 5. Mechanical properties of rubber compounds

\begin{tabular}{|l|c|c|c|c|c|r|r|}
\hline \multirow{2}{*}{\multicolumn{1}{|c|}{ Properties }} & \multicolumn{7}{c|}{ Samples(SBR/lignin/F51) } \\
\cline { 2 - 9 } & $\mathbf{1 0 0 / 0 / 0}$ & $\mathbf{1 0 0 / 0 / 1 0}$ & $\mathbf{1 0 0 / 5 0 / 0}$ & $\mathbf{1 0 0 / 5 0 / 5}$ & $\mathbf{1 0 0 / 5 0 / 1 0}$ & $\mathbf{1 0 0 / 5 0 / 1 5}$ & $\mathbf{1 0 0 / 5 0 / 2 0}$ \\
\hline Modulus at 300\% [MPa] & 1.9 & 2.7 & 3.6 & 4.0 & 6.7 & 8.5 & 10.0 \\
\hline Tensile strength [MPa] & 2.2 & 3.0 & 16.4 & 18.6 & 23.2 & 20.8 & 17.6 \\
\hline Elongation at break [\%] & 339.7 & 382.3 & 787.4 & 767.1 & 681.6 & 620.1 & 539.7 \\
\hline Permanent set [\%] & 8.0 & 8.0 & 32.0 & 36.0 & 60.0 & 59.0 & 60.0 \\
\hline Tear strength [kN/m] & 10.9 & 11.9 & 49.4 & 52.6 & 57.6 & 60.4 & 62.2 \\
\hline Hardness [Shore A] & 40.0 & 37.9 & 64.0 & 66.0 & 70.0 & 72.0 & 76.0 \\
\hline
\end{tabular}



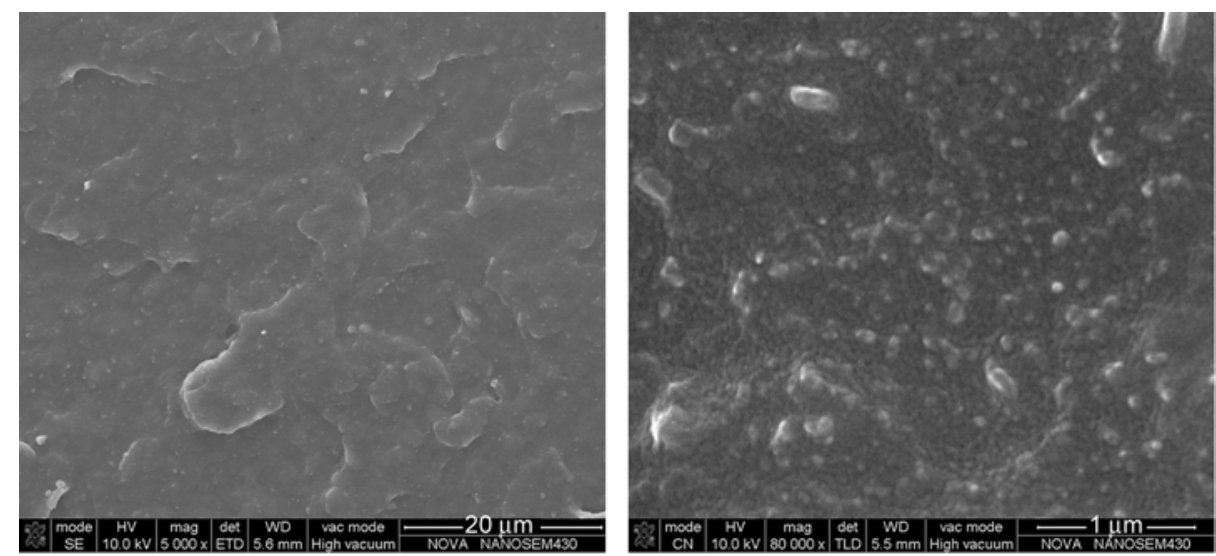

a) $5000 x$ $80000 \times$
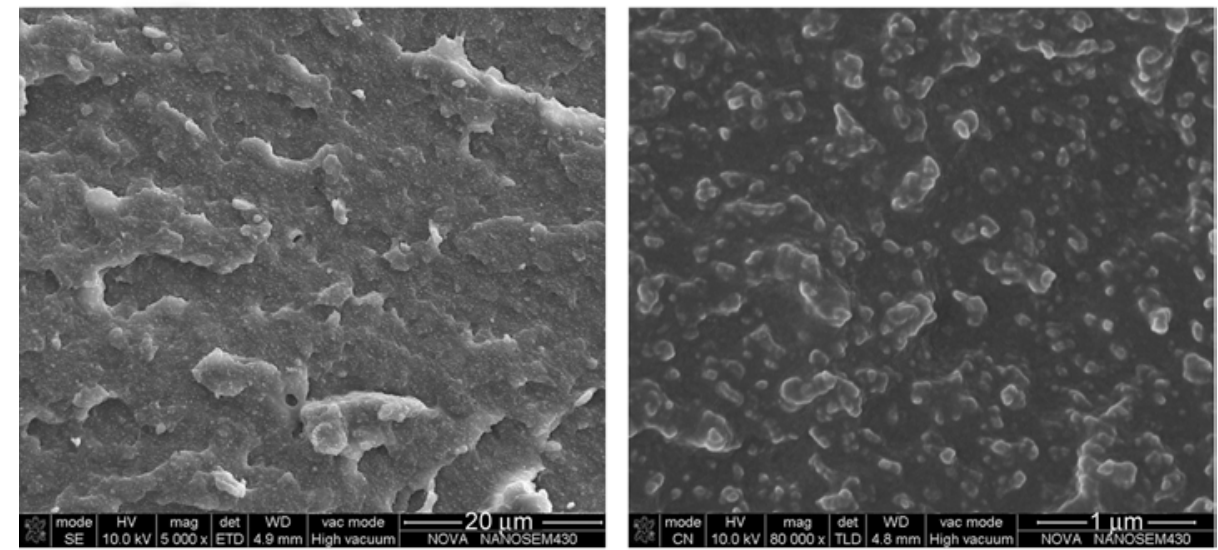

b) $5000 x$

$80000 x$

Figure 12. SEM images of the tensile fracture surfaces. (a) SBR/50lignin, (b) SBR/50lignin/20F51

of F51-lignin networks is demonstrated by the results of SEM and its glass transition temperature is observed by DMA. The lignin-F51 networks show good reinforcement towards the SBR compounds and improved initial thermal stability of the rubber composites. This novel reinforcing strategy is suitable for other rubbers, such as natural rubber and nitrile butadiene rubber, theoretically.

\section{Acknowledgements}

All the authors gratefully acknowledge National Natural Science Foundation of China (U1134005/L04) for financial supports.

\section{References}

[1] Xiao S., Feng J., Zhu J., Wang X., Yi C., Su S.: Preparation and characterization of lignin-layered double hydroxide/styrene-butadiene rubber composites. Journal of Applied Polymer Science, 130, 1308-1312 (2013). DOI: 10.1002/app.39311

[2] Sadek E. M., El-Nashar D. E., Ahmed S. M.: Effect of organoclay reinforcement on the curing characteristics and technological properties of styrene-butadiene rubber. Polymer Composites, in press (2014).

DOI: $10.1002 /$ pc.23034
[3] Liu J., Liu H-F., Deng L., Liao B., Guo Q-X.: Improving aging resistance and mechanical properties of waterborne polyurethanes modified by lignin amines. Journal of Applied Polymer Science, 130, 1736-1742 (2013). DOI: $10.1002 / a p p .39267$

[4] Griffith T. R., MacGregor D. W.: Aids in vulcanization of lignin-natural rubber coprecipitates. Lead, copper, and bismuth oxides. Rubber Chemistry and Technology, 26, 716-730 (1953).

DOI: $10.5254 / 1.3539854$

[5] Kumaran M. G., De S. K.: Utilization of lignins in rubber compounding. Journal of Applied Polymer Science, 22, 1885-1893 (1978). DOI: 10.1002 app.1978.070220711

[6] Kumaran M. G., Mukhopadhyay R., De S. K.: Network structure of lignin-filled natural rubber vulcanizate. Journal of Polymer Science: Polymer Letters Edition, 17, 399-404 (1979). DOI: $10.1002 /$ pol.1979.130170701

[7] Košíková B., Gregorová A.: Sulfur-free lignin as reinforcing component of styrene-butadiene rubber. Journal of Applied Polymer Science, 97, 924-929 (2005). DOI: $\underline{10.1002 / \text { app. } 21448}$ 
[8] Košíková B., Gregorová A., Osvald A., Krajčovičová J.: Role of lignin filler in stabilization of natural rubber-based composites. Journal of Applied Polymer Science, 103, 1226-1231 (2007).

DOI: $10.1002 /$ app. 24530

[9] Jiang C., He H., Jiang H., Ma L., Jia D. M.: Nanolignin filled natural rubber composites: Preparation and characterization. Express Polymer Letters, 7, 480493 (2013).

DOI: $10.3144 /$ expresspolymlett.2013.44

[10] Jiang C., He H., Yu P., Wang D., Zhou L., Jia D. M.: Plane-interface-induced lignin-based nanosheets and its reinforcing effect on styrene-butadiene rubber. Express Polymer Letters, 8, 619-634 (2014).

DOI: 10.3144/expresspolymlett.2014.66

[11] Frigerio P., Zoia L., Orlandi M., Hanel T., Castellani L.: Application of lignin treated with hexamethylenetetramine as a filler for elastomers. Bioresources, 9, 1387-1400 (2014).

[12] Liao Z., Wang X., Xu Y., Feng J., Zhu J., Su S.: Cure characteristics and properties of NBR composites filled with co-precipitates of black liquor and montmorillonite. Polymers for Advanced Technologies, 23, 1051-1056 (2012).

DOI: $10.1002 /$ pat.2011

[13] Cao Z., Liao Z., Wang X., Su S., Feng J., Zhu J.: Preparation and properties of NBR composites filled with a novel black liquor-montmorillonite complex. Journal of Applied Polymer Science, 127, 3725-3730 (2013).

DOI: 10.1002/app.37984

[14] Bahl K., Jana S. C.: Surface modification of lignosulfonates for reinforcement of styrene-butadiene rubber compounds. Journal of Applied Polymer Science, 131, 40123/1-40123/9 (2014).

DOI: 10.1002/app.40123

[15] Bahl K., Miyoshi T., Jana S. C.: Hybrid fillers of lignin and carbon black for lowering of viscoelastic loss in rubber compounds. Polymer, 55, 3825-3835 (2014). DOI: 10.1016/j.polymer.2014.06.061

[16] Abdul Khalil H., Marliana M., Alshammari T.: Material properties of epoxy-reinforced biocomposites with lignin from empty fruit bunch as curing agent. Bioresources, 6, 5206-5223 (2011).

[17] Yin Q., Yang W., Sun C., Di M.: Preparation and properties of lignin-epoxy resin composite. Bioresources, 7, 5737-5748 (2012).

[18] Jiang C., He H., Yao X., Yu P., Zhou L., Jia D.: Selfcrosslinkable lignin/epoxidized natural rubber composites. Journal of Applied Polymer Science, in press (2014).

DOI: 10.1002/app.41166

[19] Ye L.: Performance and mechanism of epoxy resin for reinforcement of styrene-butadiene rubber. Journal of Macromolecular Science Part B: Physics, 50, 17711779 (2011). DOI: $10.1080 / 00222348.2010 .549062$
[20] Tan J. H., Wang X. P., Tai J. J., Luo Y. F., Jia D. M.: Novel blends of acrylonitrile butadiene rubber and polyurethane-silica hybrid networks. Express Polymer Letters, 6, 588-600 (2012).

DOI: $10.3144 /$ expresspolymlett.2012.62

[21] Jiang X. L., Hu K., Yang P., Ren J.: Study on preparation and properties of water swellable rubber modified by interpenetrating polymer networks. Plastics, Rubber and Composites, 42, 327-333 (2013). DOI: $10.1179 / 1743289812 y .0000000027$

[22] Su C., Zong D., Xu L., Zhang C.: Dynamic mechanical properties of semi-interpenetrating polymer network-based on nitrile rubber and poly(methyl methacrylate-co-butyl acrylate). Journal of Applied Polymer Science, 131, in press (2014).

DOI: 10.1002/app.40217

[23] Imbernon L., Pire M., Oikonomou E. K., Norvez S.: Semi-interpenetrating networks in blends of epoxidized natural rubbers. Macromolecular Chemistry and Physics, 214, 806-811 (2013).

DOI: $10.1002 / \mathrm{macp} .201200671$

[24] Chen W., Wu S., Lei Y., Liao Z., Guo B., Liang X., Jia D.: Interfacial structure and performance of rubber/ boehmite nanocomposites modified by methacrylic acid. Polymer, 52, 4387-4395 (2011).

DOI: $10.1016 /$ j.polymer.2011.07.028

[25] Leblanc J. L.: Rubber-filler interactions and rheological properties in filled compounds. Progress in Polymer Science, 27, 627-687 (2002). DOI: 10.1016/S0079-6700(01)00040-5

[26] Sheng E., Sutherland I., Bradley R. H., Freakley P. K.: Effects of a multifunctional additive on bound rubber in carbon black and silica filled natural rubbers. European Polymer Journal, 32, 35-41 (1996).

DOI: 10.1016/0014-3057(95)00107-7

[27] Gong Z-L., Cen L., Wang S-T., Chen F-L.: Synthesis and characterization of maleated glycidyl 3-pentadecenyl phenyl ether as a functionalized plasticizer for styrene-butadiene rubber/carbon black/silica composites. Journal of Applied Polymer Science, 131, in press (2014).

DOI: 10.1002/app.40462

[28] Du M., Guo B., Lei Y., Liu M., Jia D.: Carboxylated butadiene-styrene rubber/halloysite nanotube nanocomposites: Interfacial interaction and performance. Polymer, 49, 4871-4876 (2008).

DOI: $10.1016 /$ j.polymer.2008.08.042

[29] Gu J., Chen W-J., Lin L., Luo Y-F., Jia D-M.: Effect of nanocrystalline cellulose on the curing characteristics and aging resistance properties of carbon black reinforced natural rubber. Chinese Journal of Polymer Science, 31, 1382-1393 (2013).

DOI: $10.1007 / \mathrm{s} 10118-013-1340-6$

[30] Cao X., Xu C., Wang Y., Liu Y., Liu Y., Chen Y.: New nanocomposite materials reinforced with cellulose nanocrystals in nitrile rubber. Polymer Testing, 32, 819-826 (2013). DOI: $10.1016 /$ j.polymertesting.2013.04.005 
[31] He S., Zhang L., Wu X., Lin J., Xi M., Wang Y.: Reduction of the filler network interaction in novel inner liner compound based on SBR/rectorite nanocomposite by glycerin. Polymer Composites, 33, 336342 (2012).

DOI: $10.1002 /$ pc.22152

[32] Laskowska A., Zaborski M., Boiteux G., Gain O., Marzec A., Maniukiewicz W.: Ionic elastomers based on carboxylated nitrile rubber (XNBR) and magnesium aluminum layered double hydroxide (hydrotalcite). Express Polymer Letters, 8, 374-386 (2014). DOI: $10.3144 /$ expresspolymlett.2014.42

[33] Komiya G., Imai T., Happoya A., Fukumoto T., Sagae H., Sone N., Takahashi A.: Effects of lignin derivatives on cross-link density and dielectric properties in the epoxy-based insulating materials for printed circuit boards. IEEE Transactions on Components Packaging and Manufacturing Technology, 3, 1057-1062 (2013). DOI: $10.1109 /$ tcpmt.2013.2253836

[34] Shin S., Lim D. G., Kang T., Chun H., Cho J. K.: Thermal and electrical properties of glass fiber reinforced o-cresol novolac epoxy composites cured with allylated phenol novolac hardener. Polymer International, 61, 1411-1416 (2012). DOI: $10.1002 /$ pi.4224

[35] Lin J., Wu X., Zheng C., Zhang P., Li Q., Wang W., Yang Z.: A novolac epoxy resin modified polyurethane acylates polymer grafted network with enhanced thermal and mechanical properties. Journal of Polymer Research, 21, 435/1-435/10 (2014). DOI: $10.1007 / \mathrm{s} 10965-014-0435-2$

[36] Dong Z-X., Liu M-X., Jia D-M., Zhou Y-H.: Synthesis of natural rubber- $g$-maleic anhydride and its use as a compatibilizer in natural rubber/short nylon fiber composites. Chinese Journal of Polymer Science, 31, 1127-1138 (2013).

DOI: $10.1007 / \mathrm{s} 10118-013-1310-\mathrm{z}$

[37] Sun X., Zhao F., Zhao S.: Study on dynamic fatigue properties of solution-polymerized styrene butadiene rubber T2000R. Journal of Elastomers and Plastics, 43, 469-480 (2011). DOI: $10.1177 / 0095244311402634$
[38] Wang X., Feng N., Chang S.: Effect of precured degrees on morphology, thermal, and mechanical properties of BR/SBR/NR foams. Polymer Composites, 34, 849-859 (2013). DOI: $10.1002 /$ pc. 22489

[39] Hu M., Zhao S., Li C., Wang B., Yao C., Wang Y.: The influence of different Tween surfactants on biodesulfurization of ground tire rubber by Sphingomonas sp. Polymer Degradation and Stability, 107, 91-97 (2014). DOI: $10.1016 /$ j.polymdegradstab.2014.04.025

[40] Liu X., Zhao S., Zhang X., Li X., Bai Y.: Preparation, structure, and properties of solution-polymerized styrene-butadiene rubber with functionalized end-groups and its silica-filled composites. Polymer, 55, 19641976 (2014).

DOI: 10.1016/j.polymer.2014.02.067

[41] Peng Z., Feng C., Luo Y., Yi Z., Kong L.: Structure and properties of self-assembled narural rubber/multiwalled carbon nanotube composites. Journal of Wuhan University of Technology-Materials Sience Edition, 26, 807-811 (2011). DOI: $10.1007 / \mathrm{s} 11595-011-0315-0$

[42] Grinberg F., Garbarczyk M., Kuhn W.: Influence of the cross-link density and the filler content on segment dynamics in dry and swollen natural rubber studied by the NMR dipolar-correlation effect. The Journal of Chemical Physics, 111, 11222-11231 (1999). DOI: $10.1063 / 1.480478$

[43] Garbarczyk M., Grinberg F., Nestle N., Kuhn W.: A novel approach to the determination of the crosslink density in rubber materials with the dipolar correlation effect in low magnetic fields. Journal of Polymer Science Part B: Polymer Physics, 39, 2207-2216 (2001). DOI: $10.1002 /$ polb.1194

[44] Grinberg F., Heidenreich M., Kuhn W.: A new contrast parameter for visualization of the cross-link density in rubber based on the dipolar-correlation effect. Journal of Magnetic Resonance, 159, 87-91 (2002). DOI: 10.1016/S1090-7807(02)00007-1 